\title{
Measurement of Phase Transformation Temperatures UNDER NEAR-REAL CONDITIONS USING A THERMOMECHANICAL SIMULATOR
}

\author{
Adam Stehlík, Jiř́i Vrtáček, Michal Pekovic \& Štěpán Jeníček
}
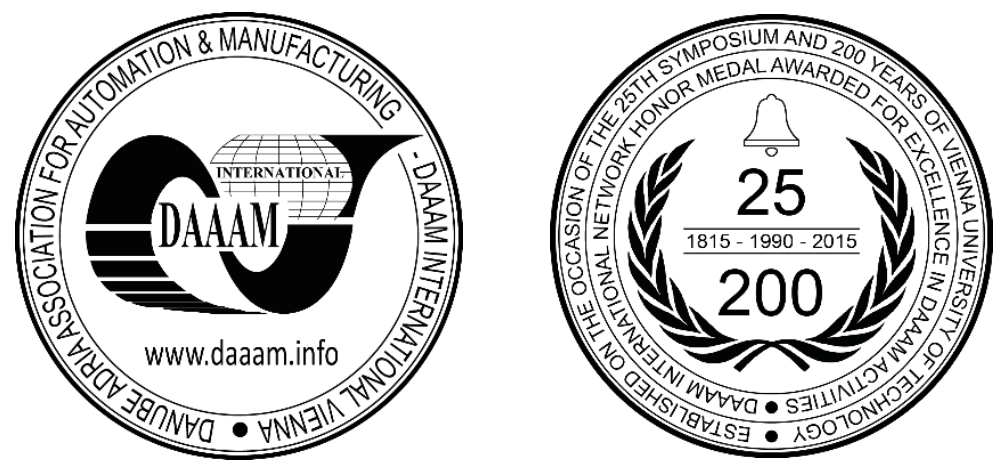

This Publication has to be referred as: Stehlik, A[dam]; Vrtacek, J[iri]; Pekovic, M[ichal] \& Jenicek, S[tepan] (2018). Measurement of Phase Transformation Temperatures Under Near-Real Conditions Using a Thermomechanical Simulator, Proceedings of the 29th DAAAM International Symposium, pp.1202-1208, B. Katalinic (Ed.), Published by DAAAM International, ISBN 978-3-902734-20-4, ISSN 1726-9679, Vienna, Austria

DOI: $10.2507 / 29$ th.daaam.proceedings. 174

\begin{abstract}
Phase transformations are normally studied under standard conditions using dilatometers and very small volumes of material. These conditions are given by historical definitions and do not fully correspond to real-world industrial processes any more. Transformation diagrams are a typical example here. They are constructed on the basis of dilatometric data measured at various cooling rates. Specimens are ordinarily cooled from temperatures to which they were brought under fixed conditions. However, real-world processes deviate from such agreed-upon conditions. The deviations often preclude accurate analysis of relevant phenomena which take place in the process. This was the motivation for exploring the possibilities of measuring phase transformation behaviour during physical simulation, while incorporating plastic deformation, which can alter the behaviour profoundly. This paper describes experiments performed on specimens of 22MnB5 steel. Metallographic observation using optical and scanning electron microscopy and HV10 hardness testing were employed. Results of the measurement were checked against metallographic findings which confirmed the accuracy and the information value of the methodology.
\end{abstract}

Keywords: phase transformations; real-world processes; 22MnB5

\section{Introduction}

Thanks to novel treatment methods, new products can offer increasingly higher quality and added value. Moreover, innovative approaches deliver production cost and energy savings. Additional benefits include reductions in air pollution and $\mathrm{CO}_{2}$ emissions. Development of most innovative and complex process chains would be unthinkable without data on manufacturing processes and materials behaviour. They are prerequisites for achieving true innovation, production efficiency and energy savings. Today, as much as in the past, the desired microstructures in advanced steels are attained using heat treatment [1] [2]. However, the specifications of today's process windows, which should lead to final properties, are much tighter. In addition, the windows are becoming still narrower. The number of their crucial parameters has been increasing. Process development and optimization are frequently based on FE simulations [3] which require accurate input data. 
With the expansion of today's knowledge base, the materials data acquired by classical methods are becoming inadequate for these simulations. Much of these data are still measured using techniques which date back more than half a century. Transformation diagrams are a typical example here. They are constructed on the basis of dilatometric data measured at various cooling rates. Specimens are ordinarily cooled from temperatures to which they were brought under fixed conditions. However, real-world processes deviate from such agreed-upon conditions. This is why new measuring methods and procedures need to be developed for measuring phase transformation behaviour during physical simulation, while incorporating plastic deformation, which can alter the behaviour profoundly. Physical simulation involves replication of a real-world process on a small specimen using a thermomechanical simulator. The specimen is therefore worked under conditions which are close to real-world production. Physical simulation is extremely useful for implementing new forming technologies and for optimizing the existing ones.

This paper aims at characterizing transformation behaviour of materials in a way which can be used for numerical modelling of complex processes and improve the accuracy and effectiveness of modelling tools. FE simulations often deliver inadequate results due to inaccurate input data, or even fail altogether in terms of the desired outcome.

\section{Experiments}

\subsection{Specimen clamping, heating and cooling}

A new methodology for characterizing transformation behaviour of materials was developed for a thermomechanical simulator [4] which offers close control of process conditions [5] (Fig. 1). The thermomechanical simulator has been developed by the University of West Bohemia [6]. It consists of a servohydraulic test machine and heating and cooling devices. Physical simulation involves thermomechanical treatment of a small volume of material in a thermomechanical simulator [6]. In an arrangement like this, accurate and rapid control of process parameters is available [7]. This means that physical simulation can be used for designing forming processes that involve very high strain rates and rapid temperature changes [8].

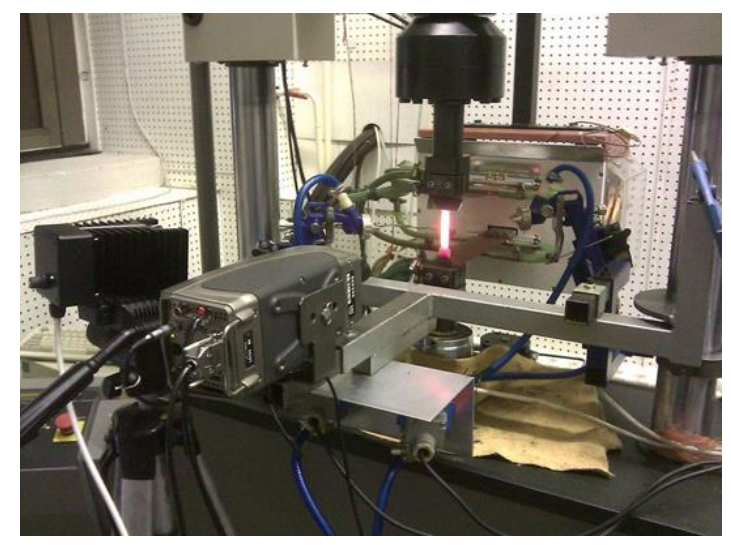

Fig. 1. Method of clamping a specimen in the test machine, adjustment of cooling nozzles and monitoring of the temperature field with a thermal imaging camera

Over time, various design changes were made to the test device and the test methods were updated. The objective was to achieve close reproduction of all stages of real-world processes. Highly-uniform temperature field and its dynamic changes were the goal of the heating stage. In terms of cooling, the focus was on the configuration of cooling nozzles to ensure that the entire gauge section of the specimen cooled uniformly and at a sufficient rate. Cooling can be provided by blast of air, water mist or water. 256 cooling intensity levels are available. The supply leads from the transformer to the grips had to be adjusted for the flat specimens (Fig. 2).

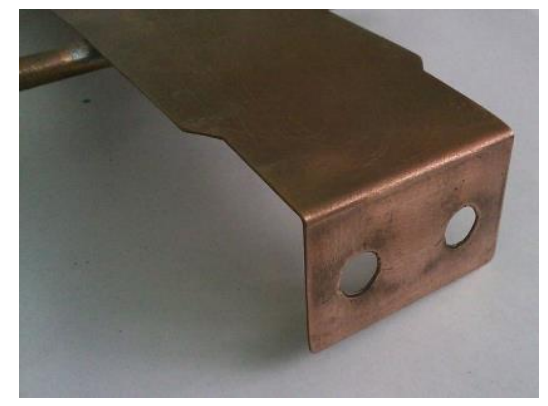

Fig. 2. Detail of the end of the power supply sheet 
Initial trials have shown that when the heating device turns off and on during heating or when heating and cooling devices operate simultaneously, it causes undesirable slope changes in the expansion plot which are difficult to distinguish from indications of phase transformations. It proved necessary to prevent the heating device from switching repeatedly during specimen cooling. One plain solution was to enter a sufficiently low temperature setpoint to ensure that the heating device does not energize when the temperature drops momentarily. The disadvantage was that the actual setpoint was thus lost from the record and the deviation from the setpoint became impossible to evaluate. The heating controller was therefore provided with an additional input that disabled heating upon a signal from one of the digital outputs of the cooling controller. Heating could then be programmed to be disabled at any time by this output, which prohibited the simultaneous operation of cooling and heating devices and the undesired activation of heating. As a result, the setpoint became easy to compare with the actual temperature and to adjust.

\subsection{Specimen optimization and analysis of temperature field}

Various shapes of the heads of specimens were proposed in an effort to obtain a homogeneous temperature field (Fig. 3). Their temperature fields were monitored with a thermal imaging camera (Fig. 4). The specimens were made by waterjet cutting [10]. From the thermal imaging camera record, both longitudinal and transverse temperature distribution in the specimens were evaluated. The objective of the specimen optimization was to minimize the impact of the temperature gradient in the transition between the gauge section and the head on the temperature field homogeneity in the gauge section.

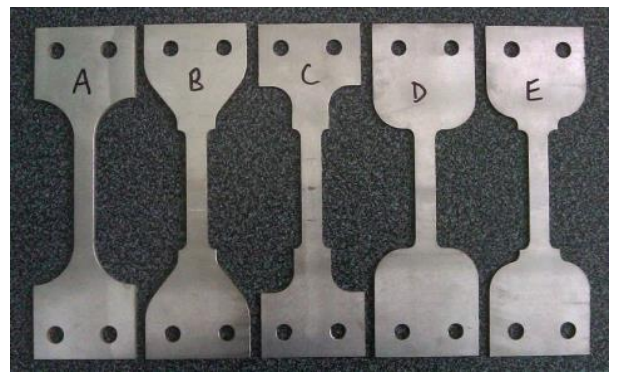

Fig. 3. Various proposed shapes of specimen heads

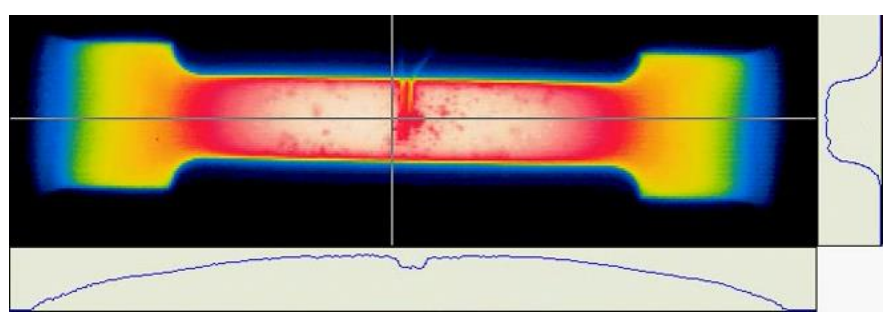

Fig. 4. Temperature field in specimen $\mathrm{C}$ during heating

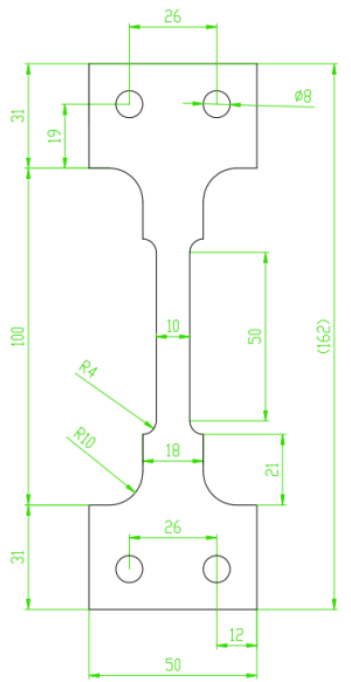

Fig. 5. Specimen shape and dimensions 
In terms of the temperature distribution, shape $\mathrm{C}$ proved to be the best variant. It was therefore used for further examination of the impact of the shape of the transition region between the gauge section and the specimen head. Four different lengths varied in $3 \mathrm{~mm}$ increments were tested. The longest variant (Fig. 5) performed best in this test and was chosen for subsequent measurement of phase transformations.

Homogeneity of temperature field was assessed during cooling as well (Fig. 6) because it is important for obtaining a reliable expansion-temperature record. Achieving the desired level of control of the temperature field was very demanding, particularly at higher cooling rates which required the use of water mist or water spray.

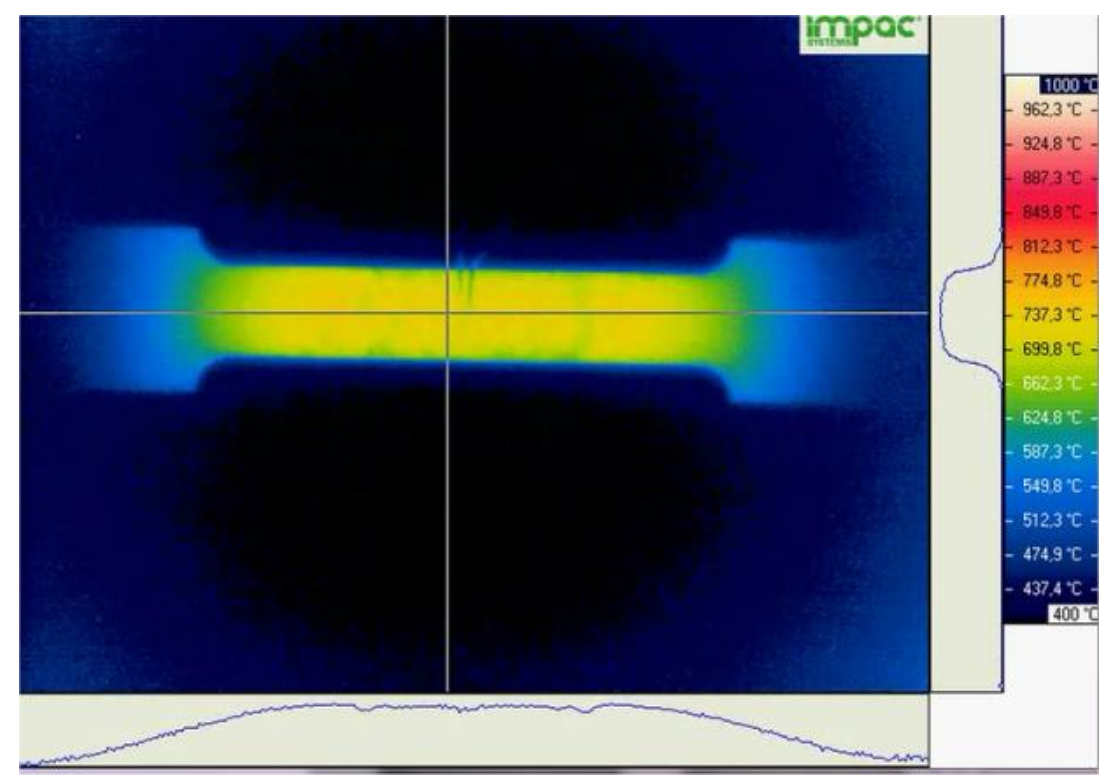

Fig. 6. Temperature field in specimen $\mathrm{C}$ during cooling

\subsection{Measurement of phase transformation processes}

The entire measurement methodology was tested on 22MnB5 martensitic hardenable steel (Tab.1) which can be used for making products with strengths up to $1700 \mathrm{MPa}$ and with features of deep-drawn parts. It is also used for presshardened parts.

Press hardening is a recently-developed technique for manufacturing complex lightweight high-strength parts for the automotive industry. It is used for high-strength components of car body: A and B pillars, door intrusion beams and body sills, frames, bumper brackets, transverse and longitudinal members and others [11].

\begin{tabular}{|l|c|c|r|r|r|r|r|r|r|}
\hline Element & \multicolumn{1}{c|}{$\mathrm{C}$} & \multicolumn{1}{c|}{$\mathrm{Si}$} & $\mathrm{Mn}$ & $\mathrm{P}$ & $\mathrm{S}$ & $\mathrm{Al}$ & $\mathrm{N}$ & $\mathrm{Cr}$ & $\mathrm{B}$ \\
\hline Content [\%] & 0.25 & 0.4 & 1.4 & 0.025 & 0.015 & 0.08 & 0.01 & 0.3 & 0.005 \\
\hline
\end{tabular}

Table 1. Chemical composition of 22MnB5 steel

\subsection{Measurement of phase transformation temperatures}

Once the entire measuring system had been set up and data collection equipment adjusted, the expansion vs. temperature dependence could be obtained. Dilatometric curves were constructed from the data. Specimens of 22MnB5 steel experienced several cooling rates: 5,25 and $60^{\circ} \mathrm{C} / \mathrm{s}$. The specimens were examined using metallographic techniques and their hardness was measured.

\subsection{Results}

At the slowest cooling rate, ferritic and pearlitic transformations were identified in the dilatometric curve of the $22 \mathrm{MnB} 5$ steel (Fig. 7). Ferrite began to form at $694^{\circ} \mathrm{C}$. The start of the bainitic transformation was detected at $558^{\circ} \mathrm{C}$. Metallographic analysis confirmed the presence of a ferritic-pearlitic microstructure with a hardness of $251 \mathrm{HV} 10$. 


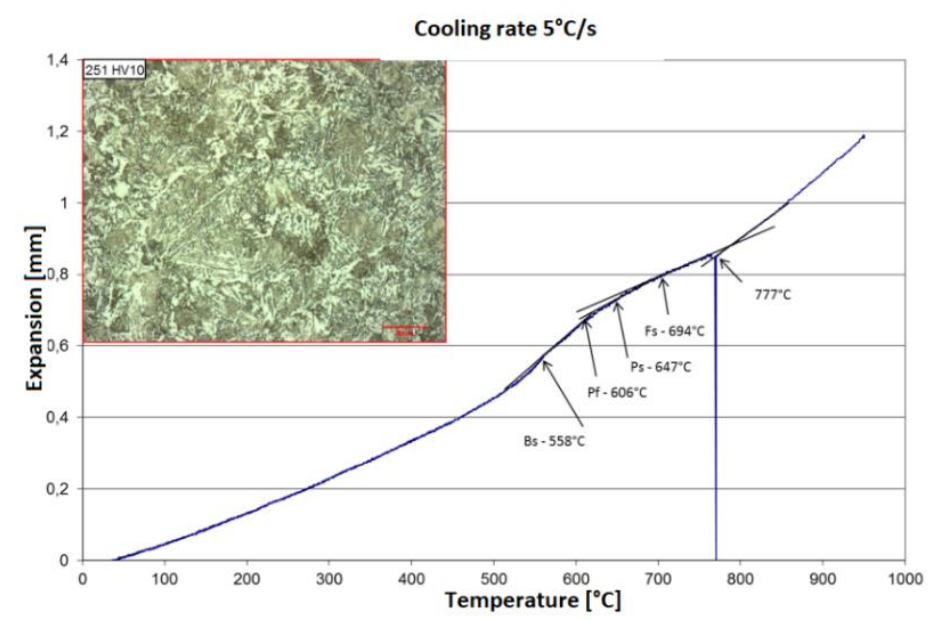

Fig. 7. $22 \mathrm{MnB} 5$ - dilatometric curve, $5^{\circ} \mathrm{C} / \mathrm{s}$, phase transformation temperatures

With increasing cooling rates, the amount of hardening phases was growing. After cooling at $25^{\circ} \mathrm{C} / \mathrm{s}$, the microstructure consisted predominantly of martensite, and some bainite (Fig. 8). Hardness increased appreciably to 458 HV10. The bainite start temperature was $548^{\circ} \mathrm{C}$. Martensite began to form at $390^{\circ} \mathrm{C}$.

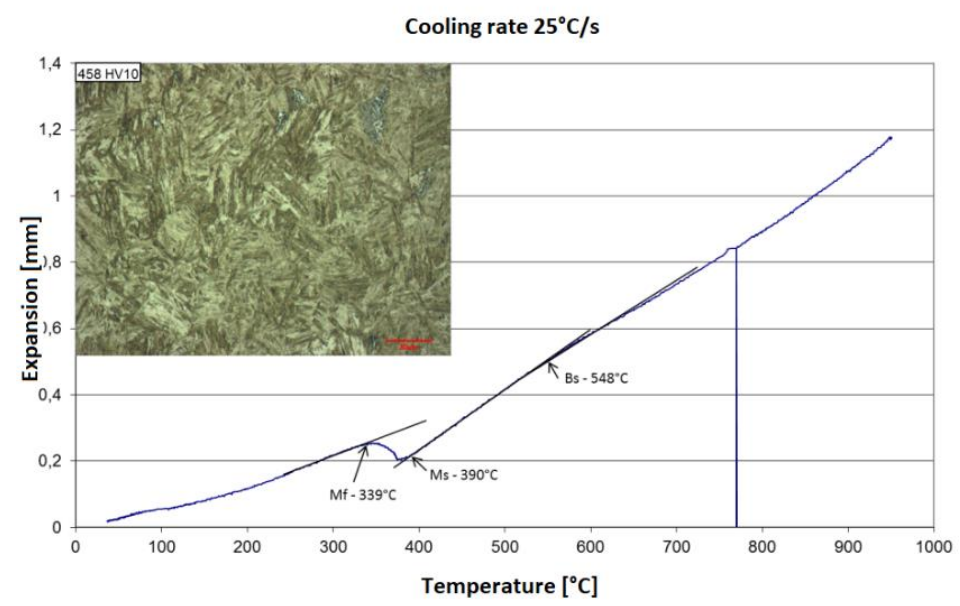

Fig. $8.22 \mathrm{MnB} 5$ - dilatometric curve, $25^{\circ} \mathrm{C} / \mathrm{s}$, phase transformation temperatures

After cooling at the fastest rate, a martensitic structure with a hardness of $471 \mathrm{HV} 10$ was obtained. This finding was confirmed by the dilatometric curve which only showed the martensitic transformation, the Ms was $354^{\circ} \mathrm{C}$ (Fig. 9).

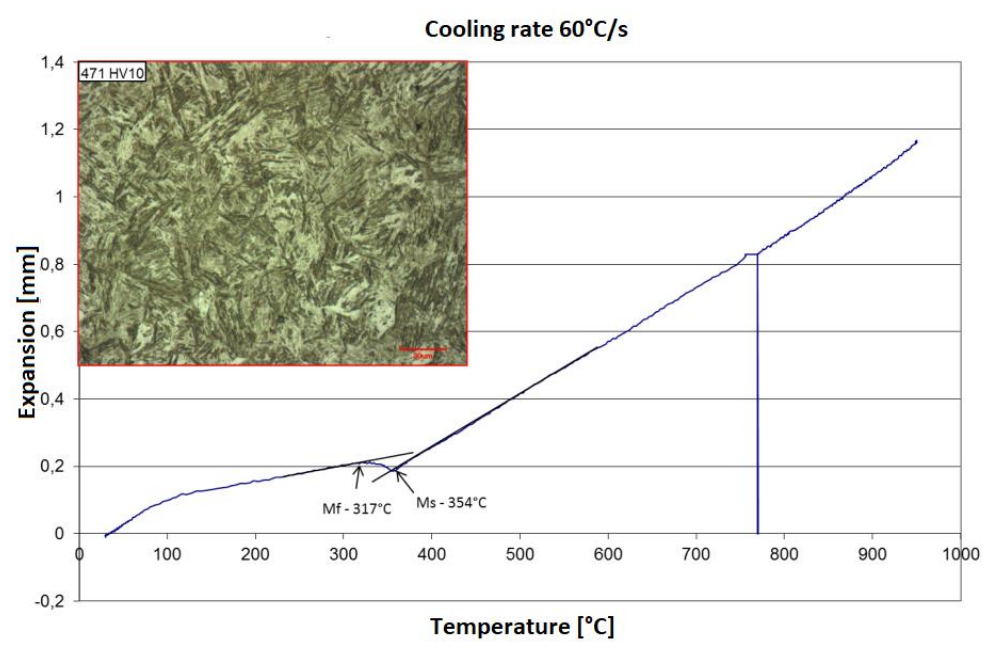

Fig. 9. $22 \mathrm{MnB} 5$ - dilatometric curve, $60^{\circ} \mathrm{C} / \mathrm{s}$, phase transformation temperatures 
Three dilatometric curves (Tab. 2) were examined for each cooling rate, to ensure that correct results are obtained and the desired gradient was achieved.

\begin{tabular}{|l|c|c|c|c|c|c|c|c|c|}
\hline & \multicolumn{3}{|c|}{$5^{\circ} \mathrm{C} / \mathrm{s}$} & \multicolumn{3}{c|}{$25^{\circ} \mathrm{C} / \mathrm{s}$} & \multicolumn{3}{c|}{$60^{\circ} \mathrm{C} / \mathrm{s}$} \\
\hline Specimen & 1 & 2 & 3 & 1 & 2 & 3 & 1 & 2 & 3 \\
\hline Fs $\left[{ }^{\circ} \mathrm{C}\right]$ & - & 712 & 694 & - & - & - & - & - & - \\
\hline $\mathrm{Ps}\left[{ }^{\circ} \mathrm{C}\right]$ & 655 & 648 & 647 & - & - & - & - & - & - \\
\hline $\mathrm{Pf}\left[{ }^{\circ} \mathrm{C}\right]$ & 613 & 614 & 606 & - & - & - & - & - & - \\
\hline $\mathrm{Bs}\left[{ }^{\circ} \mathrm{C}\right]$ & 550 & 551 & 558 & 557 & 556 & 548 & - & - & - \\
\hline $\mathrm{Ms}\left[{ }^{\circ} \mathrm{C}\right]$ & - & - & - & 396 & 396 & 390 & 355 & 355 & 354 \\
\hline Mf $\left[{ }^{\circ} \mathrm{C}\right]$ & - & - & - & 332 & 335 & 339 & - & 325 & 317 \\
\hline
\end{tabular}

Table 2. Results for 22MnB5

\section{Conclusion}

The 22MnB5 grade steel was chosen for developing a methodology for describing phase transformation processes. A test system was assembled and tested to ensure that very high cooling rates can be employed. Data management was optimized for plotting expansion-temperature curves and for finding points that indicate phase transformation temperatures. Three different cooling rates were applied.

The readings were evaluated and phase transformation temperatures were identified. Metallographic observation using optical and scanning electron microscopy and HV10 hardness testing were employed. Results of the measurement were checked against metallographic findings which confirmed the accuracy and the information value of the methodology.

\section{Acknowledgments}

The present contribution has been prepared under the project LO1502 'Development of the Regional Technological Institute under the auspices of the National Sustainability Programme I of the Ministry of Education of the Czech Republic aimed to support research, experimental development and innovation

\section{References}

[1] Kučerová, L; Aisman, D; Jirková, H \& Masek, B; Hauserová, Daniela. (2009). Optimization of q-p process parameters with regard to final microstructures and properties. Annals of DAAAM and Proceedings of the International DAAAM Symposium. 1035-1036.

[2] Bublíková, D., Vorel, I., Jirková, H., \& Mašek, B. (2016). Alternative heat treatment of MnSi steels by intercritical annealing and quenching and partitioning process. Paper presented at the METAL 2016 - 25th Anniversary International Conference on Metallurgy and Materials, Conference Proceedings, 664-669.

[3] Fabík, Richard \& Kliber, Jiří \& Mamuzic, Ilja \& Kubina, Tomas \& Aksenov, Sergey. (2012). Mathematical modelling of flat and long hot rolling based on finite element methods (FEM). Metalurgija -Sisak then Zagreb-. 51. 341-344.

[4] J. Káňa, J.; I. Vorel, I.; Ronešová, A. (2015) Simulator of Thermomechanical Treatment of Metals, In Daaam 2015. Vienna: Daaam International Vienna, pp. 0513-05018, ISBN: 978-3-902734-07-5, ISSN: 1726-9679

[5] Jenicek, S; Bublikova, D; Jirkova, H \& Kana, J (2017). Stability of Retained Austenite in High-Strength Martensitic Steels during Cold Deformation, Proceedings of the 28th DAAAM International Symposium, pp.0289-0294, B. Katalinic (Ed.), Published by DAAAM International, ISBN 978-3-902734-11-2, ISSN 17269679, Vienna, Austria

[6] Jeníček, Š., Vorel, I., Káňa, J., \& Opatová, K. (2017). The use of material-technological modelling to determine the effect of temperature and amount of deformation on microstructure evolution in a closed-die forging treated by controlled cooling. Manufacturing Technology, 17(3), 326-330.

[7] Vorel, I., Jeníček, S., Jirková, H., \& Mašek, B. (2016). Material and technological modelling of closed-die forging. Materiali in Tehnologije, 50(4), 499-503. doi:10.17222/mit.2014.220 
[8] Mašek, B.; Jirková, H.; Malina, J.; Skálová, L.; Meyer, W. (2007) Physical Modelling of Microstructure Development During Technological Processes with Intensive Incremental Deformation In Key EngineeringMaterials, Vol. 345-346, pp. 934-946

[9] Ibrahim, K., Vorel, I., Jeníček, S., Káňa, J., Rubešová, K., Opatová, K., \& Kotěšovec, V. (2016). A study of material-technological modelling for choosing the ideal cooling rate for designing production of closed die forgings using 30MNVS6 steel. Paper presented at the Annals of DAAAM and Proceedings of the International DAAAM Symposium, , 27(1) 551-555. doi:10.2507/27th.daaam.proceedings.081

[10] Jenicek, S.; Kotesovec, V.; Kalina, T. \& Masek, B. (2016). Use of Waterjet in Manufacturing Test Bars of HighStrength Steels, Proceedings of the 27th DAAAM International Symposium, pp.0219-0224, B. Katalinic (Ed.), Published by DAAAM International, ISBN 978-3-902734-08-2, ISSN 1726-9679, Vienna, Austria DOI: $10.2507 / 27$ th.daaam.proceedings.

[11] iaodong, Zhu \& Zhaohui, Ma \& Li, Wang. (2007). Current Status of Advanced High Strength Steel for Automaking and its Development in Baosteel. Rep Baosteel Res Inst. 